\title{
Commentary: Considering Assumptions in Associations Between Music Preferences and Empathy-Related Responding
}

\author{
SUSAN A. O'NEILL [1] \\ Simon Fraser University
}

\begin{abstract}
This commentary considers some of the assumptions underpinning the study by Clark and Giacomantonio (2015). Their exploratory study examined relationships between young people's music preferences and their cognitive and affective empathy-related responses. First, the prescriptive assumption that music preferences can be measured according to how often an individual listens to a particular music genre is considered within axiology or value theory as a multidimensional construct (general, specific, and functional values). This is followed by a consideration of the causal assumption that if we increase young people's empathy through exposure to prosocial song lyrics this will increase their prosocial behavior. It is suggested that the predictive power of musical preferences on empathy-related responding might benefit from a consideration of the larger pattern of psychological and subjective wellbeing within the context of developmental regulation across ontogeny that involves mutually influential individual-context relations.
\end{abstract}

Submitted 2014 November 1; accepted 2014 November 3.

KEYWORDS: music preferences, empathy-related responses, prescriptive and causal assumptions, axiology

THE exploratory study by Clark and Giacomantonio (2015) investigates whether participants' music preferences are able to predict their empathy (using the Basic Empathy Scale (BES) designed to measure cognitive and affective components of empathy). The authors argue that although music preferences have been shown in past studies to influence a range of behaviors and psychological outcomes, more research is needed "that validates music preferences as a measure of developmental accomplishments" (p. 53). They also argue for the relationship between prosocial behavior and empathy, citing investigations such as that by Greitemeyer, Osswald, and Brauer (2010), which found that playing prosocial video games increased participants' empathy concerns. Greitemeyer and colleagues suggested that listening to songs with prosocial lyrics might increase participants' empathy, which in turn might instigate increases in prosocial thoughts, affect, and behavior. With these potential causal relationships in mind, Clark and Giacomantonio examined whether music preferences predict empathy-related responses among participants in late adolescence/early adulthood. Their findings indicated a number of interesting associations in the data, although most failed to reach conventional significance levels. Of particular interest was that music preferences were found to be associated with cognitive components of empathy compared with affective and combined cognitive/affective components of empathy. The authors suggest that this might "be a function of the metaphoric, figurative, and poetic nature of music lyrics, and the cognitive processes needed to decipher meaning" (p. 61). I propose that alternative explanations and mediators/moderators might reveal themselves if we first consider and clarify some of the implicit assumptions underpinning the constructs used in the study.

\section{MUSIC PREFERENCES AND AXIOLOGY}

In describing music preferences, Clark and Giacomantonio point to the importance of music in the lives of young people, the potential for music to evoke powerful emotional responses, and the psychological functions associated with music and other multidimensional constructs such as coping and emotional regulation. We are also informed about recent investigations into individual differences in music preferences before considering ways of measuring music preferences according to types and genres of 
music. The implicit underlying prescriptive assumption is that music preferences can be equated with listening habits or how often participants report listening to particular music genres. These genres are defined, classified, and categorized in various ways and yet tend to converge around four factors, which Clark and Giacomantonio investigated and found to be: (1) "reflective \& complex" (comprising classical, jazz, folk, and blues genres); (2) "intense \& rebellious" (comprising rock, alternative, and heavy metal genres); (3) "upbeat \& conventional" (comprising country, pop, soundtracks, and religious genres); (4) "energetic \& rhythmic" (comprising rap, soul, dance, and electronica genres). Clark and Giacomantonio were concerned with the validity of existing measures of music preferences and sought to clarify the extent to which their measure is capable of "capturing" music preferences. Although it is likely that music preferences and listening habits are highly correlated, it raised the question for me of whether they are measuring the same thing.

Prescriptive assumptions may be concealing important value structures related to music preferences, which in turn may be concealing important associations between music preferences and other multidimensional constructs such as empathy. My sense is that individual differences in listening habits are indicative of a wider valuing of music and the function music serves in the lives of individuals (DeNora, 2000; Sloboda, O'Neill, \& Ivaldi, 2001). Further, the extent to which a person values music and the function that music serves in the individual's life, is more likely to impact on emotional and social competence than might be revealed through indications of listening habits alone. My question is therefore: are listening habits (i.e. how often a person likes to listen to particular music genres) capable of capturing the fundamental significance of the importance of music in a person's life and the functions music listening serves, including psychological functions such as emotional regulation, coping, and empathy-related responding? Perhaps we need to consider music preferences as a multidimensional construct consisting of both listening habits (e.g. liking a particular genre and how often particular forms, styles, or categories of music are listened to) and valuing of music (meaning, importance, and significance of music in a person's life) when exploring the relationship between music preferences and other multidimensional psychological and social constructs.

My question stems from an examination of work in axiology - the study of values, such as the nature of values, the status of values, and the distinctive nature of value judgments and propositions (Hart, 1971). Contemporary value theories have their origins in philosophical theorizing, such as Nietzsche's notion of the evaluation of values and developmental changes in values over time (Nietzsche, 1887), Brentano's work on how we base judgments of acceptance and rejection on our ideas and attitudes about what we love and hate (Albertazzi, Libardi, \& Poli, 1996), Meinong's notion of the referential meaning of our emotions and how value is contingent on emotions (Chisholm, 2005), and Perry's (1926) ideas on intrinsic value experience (interest), which entails both cognitive and affective components that are not considered to be isolated psychological constructs but rather based on a person's interaction with the environment (see also Gibson's, 1977, theory of affordances and discussion by Greeno, 1994). Even within expectancy-value theories related to Fishbein and Ajzen's $(1972,1974)$ work and uses and gratifications approaches (Arnett, 1995; Palmgreen, 1984), attitudes or the way people orient themselves to the world have been thought to be a function of (1) their expectation (belief) that an object/behavior has a particular attribute/consequence; and (2) their evaluation or the degree of affect (positive or negative) toward an attribute or behavioral outcome. It is this second component of evaluation that entails general, specific, and functional value constructs.

According to axiology and the measurement of values, before testing an individual for preferences, the person should first be tested for his or her "capacity to value in general" (Hartman, 1967, p. 38, original emphasis). Hartman provides the example of testing a person's preference for a color, such as green or red. In order to establish whether the person's preference for a specific color is more or less valid or significant, one must first test the person's capacity for "seeing color" (p. 38, original emphasis). The person's judgment of the specific preference is dependent on his or her general or functional (instrumental) valuing of the phenomenon. In other words, an individual's capacity to distinguish specific music preferences is dependent on the person's capacity for listening to music in general. It is this general valuing of music that gives meaning or significance to the choice of music preference. Further, even if two people choose the same color as their preference, the meaning and significance of their preference might be very different. For example, individuals reporting the same high levels of listening to "reflective \& complex" music genres may differ in the meaning they derive from their listening experiences or the "richness in properties" (p. 39) that they associate with their music listening. It may be that a multidimensional measure of music preferences may provide greater insight into associations between 
music preferences that are experienced at deeper and more meaningful levels, and potential relationships between psychological and subjective constructs associated with individual differences in wellbeing.

\section{EMPATHY, SYMPATHY, WELLBEING, AND PROSOCIAL BEHAVIOR}

The existence of established correlations in previous research linking empathy and prosocial behavior led the authors to suggest that if we increase young people's empathy through exposure to prosocial song lyrics this will increase their prosocial behavior. A consideration of the assumptions underpinning the construct of empathy and its relationship to people's engagement in prosocial behaviors also reveals a number of conceptual nuances. For example, when attempting to predict prosocial behavior from empathy-related responding, Eisenberg (2007) distinguishes between empathy and sympathy, and points to findings that demonstrate how sympathy (and sympathy that stems from empathy) is more indicative of relationships to prosocial behavior than empathy alone. Sympathy is defined as "an emotional response stemming from the apprehension of another's emotional state or condition, which is not the same as the other's state or condition but consists of feelings of sorrow or concern for the other" (p. 76). Eisenberg and others have argued that empathy can lead to personal distress (i.e. "a self-focused, aversive affective reaction to the apprehension of another's emotion," p. 76); therefore, a sympathetic reaction has been found to be a better predictor of prosocial behavior or "other-oriented (altruistic)" behavior (p. 79) and that moral judgments "sometimes mediate the effects of empathy-related responding" (p. 79) (see also Eisenberg, 1986).

Multidimensional phenomena such as empathy and sympathy are often considered more broadly within constructs such as psychological and subjective wellbeing. Psychological wellbeing tends to be associated with factors that promote emotional and mental health, such as: autonomy, personal growth, self-acceptance, life purpose, mastery, and positive relationships (Ryff \& Keys, 1995; Ryff \& Singer, 1998). These factors also relate well to frameworks supporting positive youth development programs, which Catalano et al. (2004) describe as approaches that seek to promote bonding, social, emotional, moral, and behavioral competence, and that seek to foster resiliency, self-determination, spirituality, self-efficacy, positive identity, and belief in the future, while also providing recognition for positive behaviors and opportunities for prosocial involvement. Subjective wellbeing tends to be associated with three main components: life satisfaction, the presence of positive mood, and the absence of negative mood, together often summarized as happiness (Diener \& Lucas, 1999). Ryan and Deci (2001) describe how subjective wellbeing fits within expectancy-value theories; they suggest, "well-being is a function of expecting to attain (and ultimately attaining) the outcomes one values, whatever those might be" (p. 145). Directions for future research aimed at understanding the predictive power of musical preferences on empathy-related responding might benefit from a consideration of the larger pattern of psychological and subjective wellbeing within the context of developmental regulation across ontogeny that involves mutually influential individual-context relations.

\section{NOTES}

[1] Correspondence can be addressed to: Dr. Susan O'Neill, Professor, Faculty of Education, Simon Fraser University, 8888 University Drive, Burnaby, British Columbia, V5A 1S6, Canada. E-mail: sao@sfu.ca

\section{REFERENCES}

Albertazzi, L., Libardi, M., \& Poli, R. (Eds.) (1996). The school of Franz Brentano. Dordrecht, The Netherlands: Kluwer Academic.

Arnett, J. J. (1995). Adolescents' uses of media for self-socialization. Journal of Youth and Adolescence, 24(5), 535-49.

Catalano, R. F., Berglund, M. L., Ryan, J. A. M., Lonczak, H. S., \& Hawkins, D. (2004). Positive youth development in the United States: Research findings on evaluations of positive youth development programs. The ANNALS of the American Academy of Political and Social Science, 591, 98-124. doi: $10.1177 / 0002716203260102$ 
Chisholm, R. M. (2005). Objectives and intrinsic value. In T. Ronnow-Rasmussen \& M. J. Zimmermand (Eds.), Recent work on intrinsic value (pp. 171-179). Dordrecht, The Netherlands: Springer.

Clark, S. S., \& Giacomantonio, S. G. (2015). Toward predicting prosocial behavior: Music preferences and empathy differences between adolescents and adults. Empirical Musicology Review, 10(1), 50-64.

DeNora, T. (2000). Music in everyday life. Cambridge: Cambridge University Press.

Diener, E., \& Lucas, R. E. (1999). Personality and subjective well-being. In D. Kahneman, E. Diener, \& N. Schwarz (Eds.), Well-being: The foundations of hedonic psychology (pp. 213-229). New York: Russell Sage Foundation.

Eisenberg, N. (1986). Altruistic emotion, cognition, and behavior. Hillsdale, NJ: Laurence Erlbaum.

Eisenberg, N. (2007). Empathy-related responding: Its role in positive development and socialization correlates. In R. K. Silbereisen \& R. M. Lerner (Eds.), Approaches to positive youth development (pp. 7591). New York: Sage.

Fishbein, M., \& Ajzen, I. (1972). Beliefs, attitudes, intentions and behaviour: An introduction to theory and research. Reading, MA: Addison-Wesley.

Fishbein, M., \& Ajzen, I. (1974). Attitudes towards objects as predictors of single and multiple behavioural criteria. Psychological Review, 81(1), 29-74.

Gibson, J. J. (1977). The theory of affordances. In R. Shaw \& J. Bransford (Eds.), Perceiving, acting, and knowing: Toward an ecological psychology (pp. 67-82). Hillsdale, NJ: Erlbaum.

Greeno, J. G. (1994). Gibson's affordances. Psychological Review, 101(2), 336-342.

Greitemeyer, T., Osswald, S., \& Brauer, M. (2010). Playing prosocial video games increases empathy and decreases Schadenfreude. Emotion, 10(6), 796-802.

Hart, S. L. (1971). Axiology--theory of values. Philosophy and Phenomenological Research, 32(1), 29-41.

Hartman, R. S. (1967). Formal axiology and the meaning of values. The Journal of Value Inquiry, 1(1), 3846.

Nietzsche, F. (1887). The genealogy of morals (H. B. Samuel, Trans.). New York: Boni and Liveright.

Palmgreen, P. (1984). Uses and gratifications: A theoretical perspective. In R. N. Bostrom (Ed.), Communication yearbook 8 (pp. 61-72). Beverly Hills, CA: Sage.

Perry, R. B. (1926). General theory of value. New York: Longmans, Green and Company.

Ryan, R. M., \& Deci, E. L. (2001). On happiness and human potentials: A review of research on hedonic and eudaimonic well-being. Annual Review of Psychology, 52, 141-166.

Ryff, C. D., \& Keys, C. L. M. (1995). The structure of psychological well-being revisited. Journal of Personality and Social Psychology, 69, 719-727.

Ryff, C. D., \& Singer, B. (1998). The contours of positive human health. Psychological Inquiry, 9, 1-28.

Sloboda, J. A., O'Neill, S. A., \& Ivaldi, A. (2001). Functions of music in everyday life: An exploratory study using the Experience Sampling Method. Musicae Scientiae, 5(1), 9-32. 